\title{
Educational Game "Mengenal Indonesia" as a Medium to Introduce Indonesia to the Kids
}

\author{
Falahah $^{1} \&$ Fadhila Alinda Irrahali ${ }^{1}$ \\ ${ }^{1}$ Informatics Department, Widyatama University, Bandung, Indonesia \\ Correspondence: Falahah, Informatics Department, Widyatama University, Bandung, Indonesia. E-mail: \\ falahah@widyatama.ac.id
}

Received: April 04, 2018

Accepted: September 25, 2018

Online Published: May 10, 2019

doi:10.5430/ijhe.v8n3p47

URL: https://doi.org/10.5430/ijhe.v8n3p47

\begin{abstract}
Educational game is a game especially for the kid, that contains educational materials designed in an interactive game that aims to improve intelligence as well as providing knowledge to the users. The opportunity to make android-based education game is open wide, especially the game that exploit local content. In this research, we will develop the education game that has the main goal to introduce Indonesia to the learners. Games that will be built is android-based game that explore the knowledge or specific fact about certain region or provinces in Indonesia, so it will called as "Mengenal Indonesia". This game is expected can act as a learning medium to introduce about Indonesia to the student, in interesting way. The game also be equipped with quiz about specific fact on the region that selected by the player. The game is built through ADDIE model as an approach. ADDIE (Analysis, Design, Development, Implementation, and Evaluation) is an approach that common use in design a learning content. The tools that used to build the game is FlashDevelop and using ActionScript 3.0 as programming language. After the game built, we conduct the survey to test the respond of the user. The result show that most of the user feel "Mengenal Indonesia" can help them improving knowledge about Indonesia. Therefore, it is necessary to build the game that has the content the knowledge about Indonesia. This paper will discuss the approach, design and making of educational game that contains information about Indonesia area. This content is selected because currently there is no educational game with a similar content available in the market and this content can be act as additional resource on the Social Sciences subject at elementary school level. The game, we call as "Mengenal Indonesia", previous name is "know your country", focusing to introduce some unique aspect about specific region in Indonesia. The source of knowledge we take from the book "RIPUT" (Ringkasan Pengetahuan Umum), that contains common knowledge about Indonesia, such as the longest river, the highest mountain, the fact about certain place in Indonesia, and many more. The game was built using ADDIE approach, that consist 5 steps: analysis, design, deployment, implementation, and evaluation. The game was built using FlashDevelop and ActionScript 3.0 as language script.
\end{abstract}

Keywords: game, educational game, ADDIE, Indonesia

\section{Introduction}

In digital native generation, the new generation is born with the digital environment. The new generation can access digital gadget easily than previous ones. They can adapt and use the technology easier than before, and with the internet presence, it make them more easily access information from multiple sources quickly. On the other hand, the development of android technology is rapidly increasing and more and more content in the environment android app gives users the ease to choose the application as desired. These apps can be easily accessed and some of them free available at google playstore. There is many educational game available in the google playstore such as for learning math, English, clock, religion (such as shalat, doa) and many more. Most of these game is designed for the kid and provide intuitive interface and easy to be played. But, the game that introduce Indonesia is not much, some of them are focusing the content in the cultural aspect, some in language. The game that choose Indonesia as "theme" is available, but some of them is another version of the game that already popular, and it is not an educational game.

\section{Literature Review}

\subsection{Educational Game}

Education game can be categorized as serious game, as refer to terminology of serious game, which are computer games and simulation approaches and/or technologies, which cover just about any non-game industry. Games that 
are COTS (commercial off-the-shelf) that used for non-entertainment purposes may be considered a serious game. Serious games include all aspects of education, which are teaching, training and informing, at all ages. Serious games can be applied to many spectrum, include education. The benefits of serious game in education are (a) allow the learners to experience situations like the real worlds, (b) engage the user in pedagogical journey, and (c) enable improved self-monitoring, problem recognition and problem solving. Serious games also become increasingly popular as an educational tools in schools. (Katsaliaki, Korina, \& Mustafee, Navonil,, 2012)( Koumje, G. F., 2018)

Game can consist of set of element. Ten ingredients of great games identify the main component such as : self-representation with avatars, three-dimensional environments, narrative context, feedback, reputations, ranks and level, marketplaces and economies, competition under rules that are explicit and enforced, teams, parallel communication system, and time pressure. (Detering, Sebastian, Dixon, Dan, Khaled, Rilla, Nacke, Lennart, 2016)(Tabar, C., 2018) Education game has some principles such as (McClarty, K., Orr, A., Frey, P.M., Dolan, R.P., Vassivela, V., McVay, Aaron., 2012) (Ali, H. E., 2017):

a. Individualization: the content should made based on the individual need of learner. The game can adopt individual level of the player

b. Active feedback: there is a feedback based on the speed of player ability, to improve the learning process and reduce the lack of player's knowledge according to the content that delivered. Game usually provide high speed feedback and contextual.

c. Active learning: there is a tendency to involve the learner actively to create new development knowledge, and game can provide the environment to support this process.

d. Motivation: the learner is motivated by the reward that is given on playing activity. Game can engage the player in many hours to achieve the goal.

e. Social: knowledge is a social participation process.

Game can be played with multiplayer mode.

f. Scaffolding: the player is challenged gradually by increasing the level of difficulty. It is implemented in game by design the game in multilevel.

g. Transfer: learner can transfer their ability to the others, in game, the player can transfer information from one context to another context.

h. Assessment: each individual has a chance to assess their achievement and can compare to the others.

\subsection{ADDIE Method}

ADDIE is an acronym for Analysis, Design, Development, Implementation, and Evaluation. ADDIE Model is one of the instructional system design model showing the basic steps of learning system that is simple and easy to learn. This model consists of five main phases or stages, which are (Muruganantham, D, 2015)(Okpiliya, F. I., Osah, C., Okwakpam, I., \& Ekong, A., 2016):

a. Analysis, the first step in the model is the ADDIE analysis. The analysis stage is a stage of collecting information that can be used as material for making the product, in this case the product that would be made is a learning media, such as games. Phase analysis is divided into needs assessment, problem identification and task analysis

b. Design, is the second step of ADDIE model. The design stage is the design phase of the product to be built. The design stage is divided into six sections, which are Materials Selection, Use Case Diagram, Sequence Diagram, Flowchart, State chart Diagram and Storyboard.

c. Development. The third step in ADDIE model is development. In this stage we translate the design output into a product. The development phase consists only one part, which is the implementation of Interface.

d. Implementation, is the next step in ADDIE model. The implementation phase is the testing phase products have been made in the development phase, tests that would be conducted is Beta Testing. This test would be conducted by students as the users.

e. Evaluation, is the last step of ADDIE model. Evaluation stage is the stage of determining the feasibility of the products are made based on an assessment of beta testing. Evaluation phase consists of only one part, namely the evaluation. 


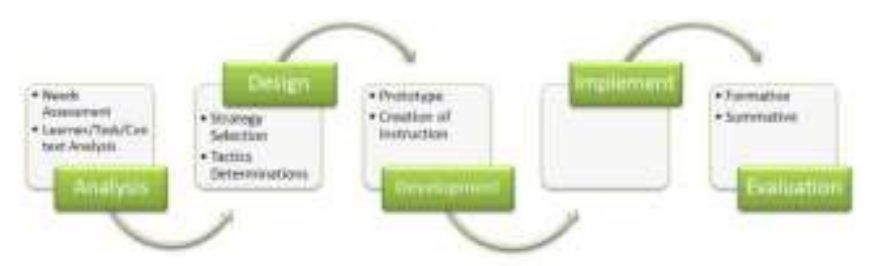

Figure 1. The Steps in ADDIE model [4]

\section{Analysis and Design}

\subsection{Game Development Stage}

The game will be developed through several stage:

a. Identify the game theme. The first stage is to define the game theme. In this case, we choose the theme of this game is educational game. The goal of this game is game for the kid to learn about Indonesia.

b. Identify the game content. The game content should be defined to ensure the goal of the game can be achieved. We define the content of this game is provide the knowledge about specific area in Indonesia, such as the river, mountain, local legend, myth, unique animal or fruit and so on. The source of knowledge that will be embedded in this game is taken from the book "RIPUT"

(Rangkuman Ilmu Pengetahuan Umum Terlengkap) that consist of common knowledge about region in Indonesia. The book is published in 2013 and we assume there is not much update in the content during 2013-2015 (Waranurastuti, V., 2013)(Moustafa, H., Tourkia, F. B., \& Ramadan, R. M., 2017).

c. Design the main storyboard. In this stage, we define the main storyboard of this game. The game will display the Indonesia Archipelago in a Map, and player can choose the island. For the island that has chosen, the player can choose the specific province. For example, for Java Island, the player can choose West Java, East Java or Central Java. The game then will display the unique fact about the province that had chosen.

d. Design the asset which include design the interface, character, background, and all the object that would displayed on the screen. For each asset, we should defined whether it will be built from the scratch or we can utilize the free license asset on the internet. If it need to be built, we have to prepare the asset first. Most of the images, characters, and objects on this game is built by the developer, and only limited asset is taken from free resource.

e. Choose the development tools. Tools that is chosen by the developer is FlashDevelop, because we decide to build the game using flash, and also the size of file of final result is relatively small.

f. Build the game, is the implementation stage of all concept that has designed and prepared.

\subsection{Game Description}

The first stage on ADDIE model is to analyze the requirement. It will be done by several stage such as: needs assessment, problem identification, and task analysis. (Wang, Z., Cheng, L., \& Wang, H., 2014)

\subsection{Needs Assessment}

Needs assessment is the stage when we need to declare the problem need to resolve. In this case, we declare the existing condition that there is lack of attention into information about Indonesia. Most of them do not have sufficient knowledge about our country, and they are more interested in the culture of the outside.

On the other hand, the more familiar the children with gadget open the opportunities to convey messages and information through the gadget. Therefore, it is necessary to provide a game that can be played on mobile gadgets, with attractive design, and contains knowledge and information about Indonesia. The information is packaged in a game expected to attract children to play as well as increase their knowledge of Indonesia.

Based on the above description, we can identify the characteristic of the user of the game as follows: elementary-junior high school students, with the lowest level of at least grade 3 elementary school, can use a smart-phone or tablet, and love to play the game.

Other consideration is the option of game format should be made. Game can be made in the format of a video game, but the video game is constrained condition that the game can not be played anywhere, because it requires certain devices 
such as televisions, game consoles (XBOX, Playstation, Nintendo), game storage (memory / CD), and space to operate. Therefore, games that can be played on smartphones is seen as the most appropriate solution.

\subsection{Problem Identification}

Based on the results of the previous assessment we can identification the problem that needs to resolve as follows:

a. How to make the game in the form of applications that can run on mobile devices, in this case the smartphone or tablet.

b. How to make the game that can be played on the Android operating system, due to the Android operating system is relatively most common on smartphone or tablet.

c. How to provide a game that has content that include information about Indonesia. The content should refers to the general knowledge of Indonesia relevant to students on school grade levels range between grade 3 elementary school and grade 3 junior high school.

d. The game should be made easy to operate, lightweight, simple, and attractive, thus encouraging users to play.

3.5 Task Analysis

Task analysis is a stage to define the task that should fulfill by the game that will be built. In this case, the game is expected be able to:

1. Provide the information about Indonesia in attractive playing scenario, so it will encourage the user to play it.

2. Measure the user's knowledge about Indonesia

3. Be played in smartphone or gadget that using Android as operating system. (Al Zoubi, S. M., 2015)

\subsection{Game Design}

The second stage in ADDIE model is design. The design stage consist of several activities such as: define the content, define the scenario through storyboard, define the game features, and modeling the game as a software. For modeling, we choose UML as a tools, so we will use some common diagram such as use case diagram, sequence diagram, activity diagram, and state chart diagram.

\subsection{Content}

Content of the game will refer to a book entitled RIPUT (Rangkuman Ilmu Pengetahuan Umum Terlengkap) by Venti Waranurastuti (Waranurastuti, V., 2013). The book consist information about Indonesia such as geographical position, social culture condition, history, and other relevant information. However, the book consist the common information that suitable for any age, so we need to put a limitation of the content based on syllabus from Ministry of Education and Culture that released on 2012 according to social science material for the elementary school and junior high school.

After define the scope of material that will be available in the game, the next step is to identify the content that would put in the game. In this case, we choose to put information about province, geographical border, the capitol city, the traditional house, traditional art, mountain, local heroes, history, historical building, historical artifact, island, flora and fauna, local airport and river.

\subsection{Features}

The game will consist some menu with basic features such as play the game, choose setting (to adjustment volume of background music), view information, view help and exit the game. Figure 2 display the basic features of the game.

\subsection{Scenario}

The scenario of the game will define through the storyboard. Table 1 show the example of storyboard for action "play the game". The storyboard will display three important aspect of scenario: interface design, description of action that should be done by the player, and asset that needs. 


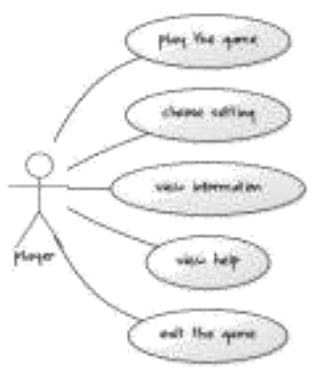

Figure 2. Use Diagram of Game "Mengenal Indonesia"

Table 1. Storyboard for "Play the Game"

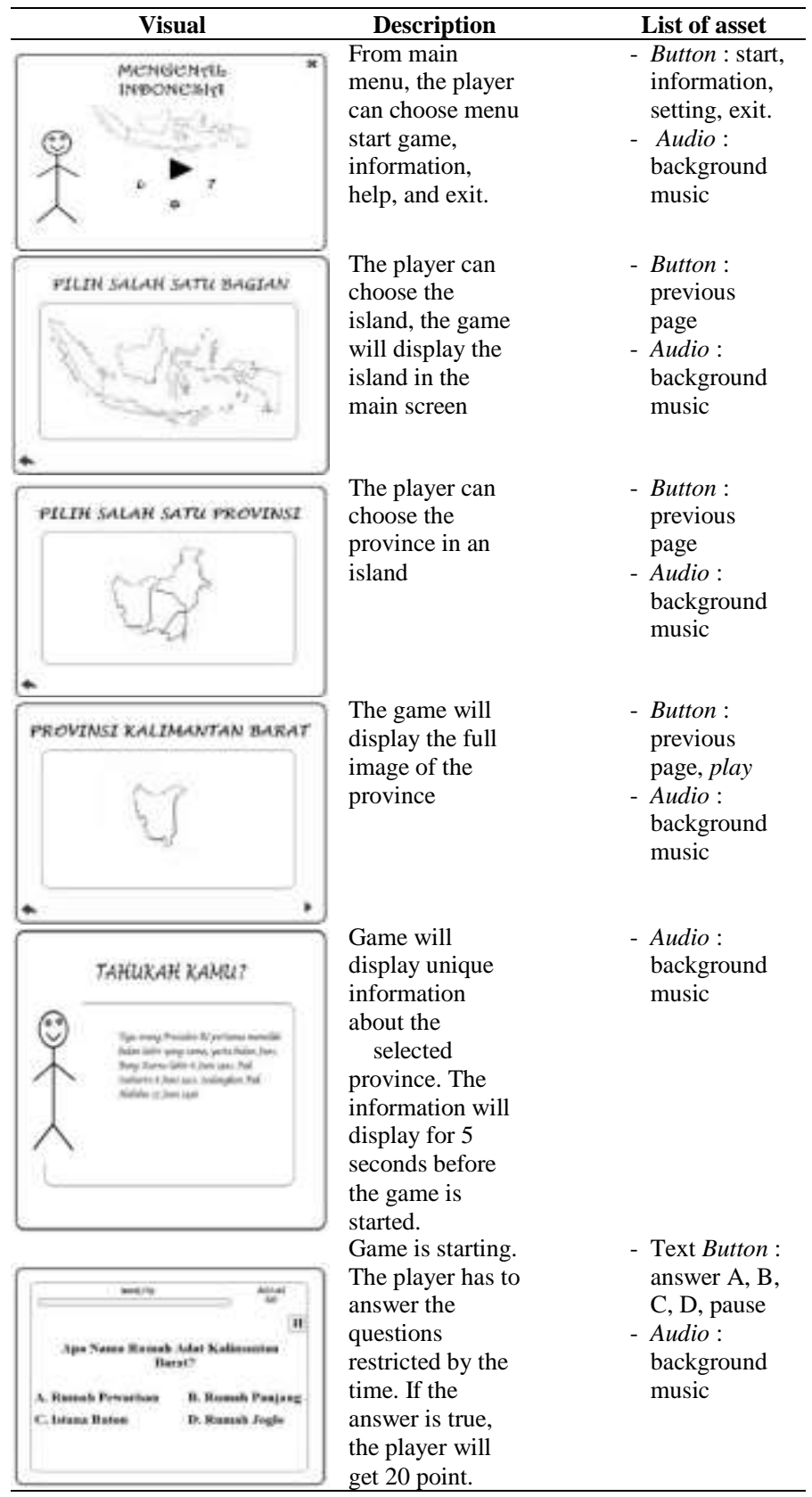




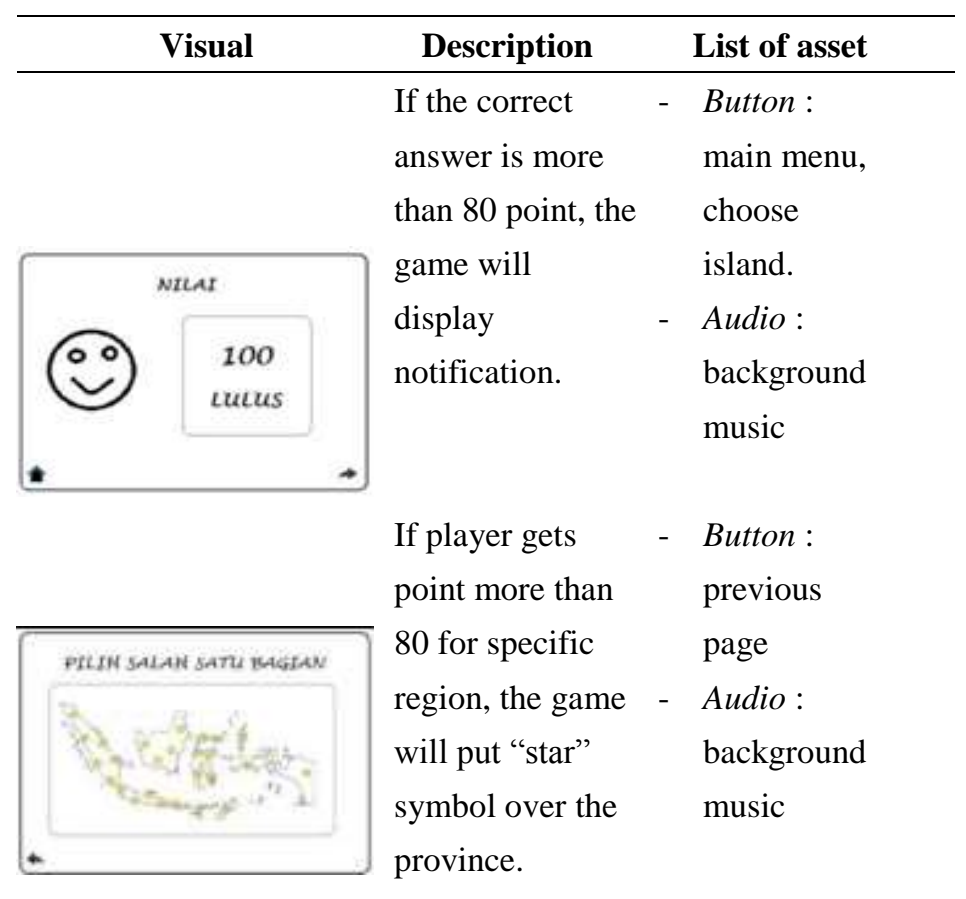

\section{Implementation and Evaluation}

\subsection{Implementation}

On this paper, we will not cover the discussion on development stage, but will display the example of design implementation. After define the interface design and storyboard, we implement the design as shown below. Figure 3 is the implementation of main display on action

"Play the game". The buttons 'exit', 'start', 'information', 'setting', and 'help' are numbered 1,2,3,4,5 respectively (figure 3).

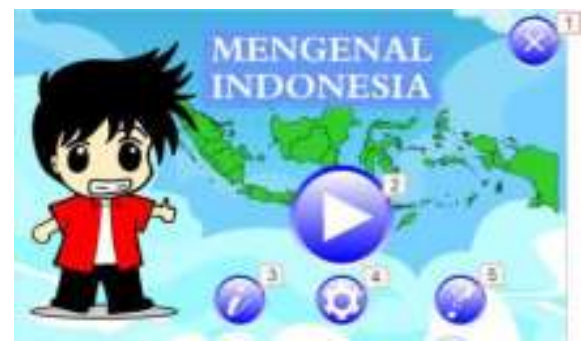

Figure 3. Main Menu

Figure 4 show the screen after the player push "start" button. The screen will display the main island in Indonesia: Sumatera, Java, Kalimantan, Sulawesi, Bali and Lombok, and Irian.

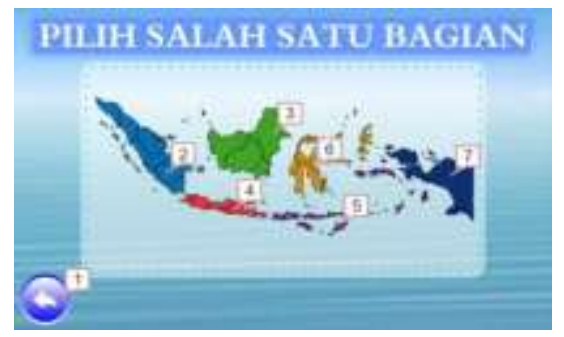

Figure 4. The Map of Indonesia 
The next step is the player can choose the Island. Figure 5 display the screen after the player choose Java island. The screen will display 3 province in Java: West Java, Central Java, and East Java.

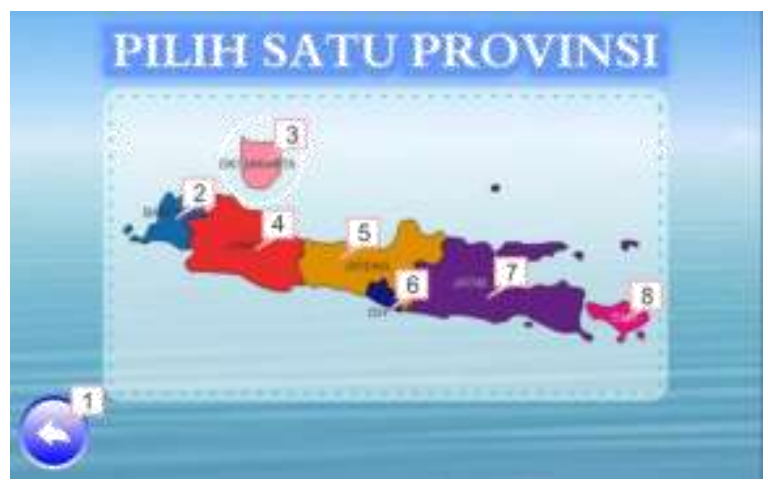

Figure 5. Map of Selected Island

After player choose the province, the game will display some fact according to the selected province, as seen on figure 6. The information will automatically disappear after 5 seconds and the player will face the series of questions as displayed in figure 7.

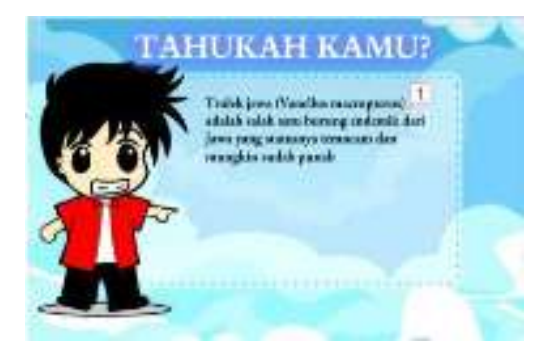

Figure 6. Fact about selected province.

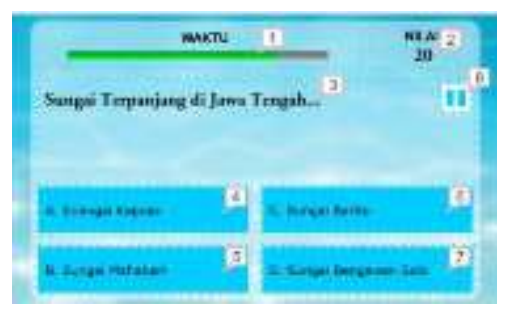

Figure 7. Question about selected province

When player can answer the question and get point bigger than 80 , the game will put an asterisk on the province.

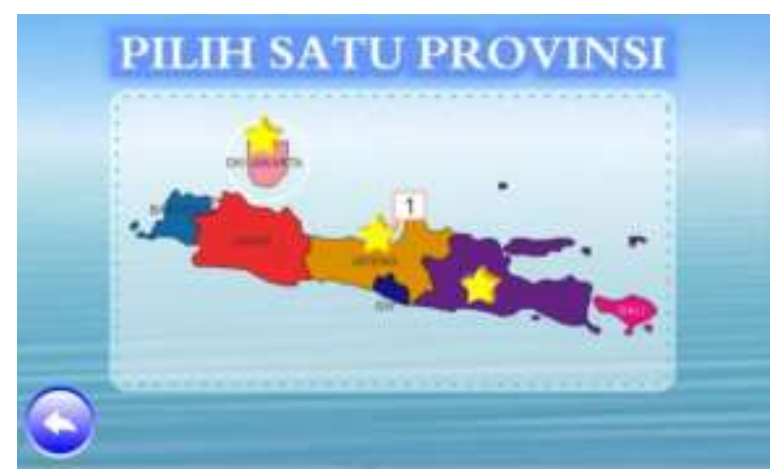

Figure 8 . The asterisk in the province that has been completed to answer the question and get a point more than 80 


\subsection{Evaluation}

The last step in ADDIE model is evaluation. We could not make a summative evaluation because we do not aim to put the game as "formal" assessment tools, instead, we will use the game as a "teaser" or "complement" of formal assessment. So we make a questionnaire to assess the opinion from user (player) about the game. We conduct the survey on 40 students and get the result as displayed in table 2 . The evaluation consist of three section. First section is to evaluate the game as a software product, second section is to evaluate the content of the game, whether the content is suitable to support the goal of game, which is to improve the knowledge of the player about Indonesia, and third evaluation is to measure the impact of play the game on the knowledge of player.

First section will focus on game usability evaluations, that means we evaluate ease of use, ease of learning, and how the player enjoy the game. Usability consist of 5 factor (Hussain, A., Abbas, S.A.A., Abdulwaheed, M.S., 2015), but on this research we set to evaluate only 3 factors above. Second section is to evaluate the content, we evaluate three factors: completeness, relevancy and presentation. Third factors is to evaluate the impact to the user, we evaluate how the user can learn using this game. The last stage is to know overall player's perception about this game.

We compiled a list of questions based on the targets of evaluation as mentioned above, practically, as in table 2. This question is given in the form of a statement and answer "Yes" and "No". We calculated the percentage of "Yes" answer against total respondents.

Table 2. Evaluation of Player's Perception

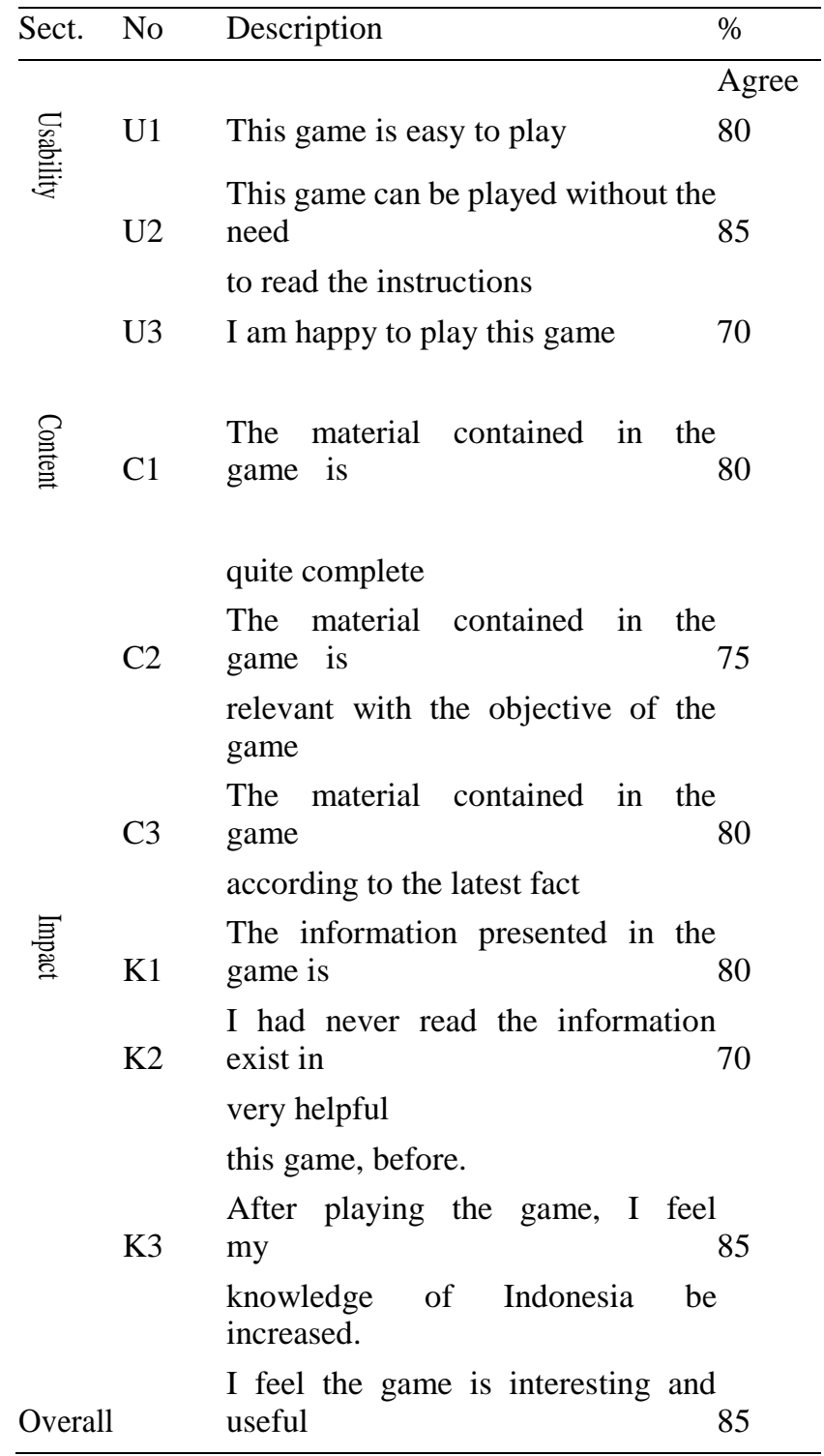


As we can see from table above, most of the respondents agree to the statement that mentioned in questionnaire. Based on this data, we can conclude that the game "Mengenal Indonesia" can be used as a tool to learn about Indonesia. The game can be improved by adding some content or some features such as connect to the online database or search engine so for each area that had chosen by the player, the game can display additional information that might be already available in the internet.

\section{Conclusion}

According to our experience in development an educational game that would be act as a tools to introduce Indonesia to the students, we can conclude some interesting point such as (Jabarullah, N.H. and Hussain, H.I., 2019)(Jabarullah, N.H. \& Hussain, H.I., 2018):

1. The game can be used as a tools to measure how far we know about Indonesia, by answering the question about fact and information about specific region in Indonesia.

2. The game was built using ADDIE model as an approach that common in development of learning material which consist 5 stage, started from analysis, design, development, implementation and evaluation. To implement full context of ADDIE model, we need prepare suitable asset and material. On this research, we use ADDIE model as a practical framework.

3. The evaluation result show that the game that has built, is able to fulfill the objective of the game, that is to provide the tools for learn about Indonesia for the students, so the learning process can be done in ease and enjoyable.

The future improvement opportunities on this game include adding some features such as connect to the internet or online database, so the knowledge will be provided directly from the actual and real time resource.

\section{References}

Al Zoubi, S. M. (2018). The Significance of Error Analysis in Written Production: A Case Study of Ajloun National University Students. International Journal of English Language and Literature Studies, 7(4), 150-159. https://doi.org/10.18488/journal.23.2018.74.150.159

Ali, H. E. (2017). Phase Transfer Synthesis of Novel Based Surfactants: Role of Biocorrosion Inhibition. Global Journal of Social Sciences Studies, 3(1), 43-55. https://doi.org/10.20448/807.3.1.43.55

Detering, Sebastian, Dixon, Dan, Khaled, Rilla, Nacke, Lennart. (2016). From Game Design Elements to Gamefulness : Defining "Gamification", accessed from https://www.cs.auckland.ac.nz/courses/compsci747s2c/1 ectures/paul/definition-deterding.pdf, on February 2016.

Hussain, A., Abbas, S.A.A., Abdulwaheed, M.S. (2015). Usability Evaluation of Mobile Game Application: A Systematic Review. International Journal of Computer and Information Technology, 4(3).

Jabarullah, N.H. \& Hussain, H.I. (2018). Comparison of Higher TVET Education and 'Normal' Academic Education: The Determinants of Electrical Engineering Students' Performance. International Journal of Engineering \& Technology, 7(4.29), 82-85.

Jabarullah, N.H. \& Hussain, H.I. (2019). The Effectiveness of Problem-Based Learning in Technical and Vocational Education in Malaysia. Education + Training.https://doi.org/10.1108/ET-06-2018-0129.

Katsaliaki, Korina, \& Mustafee, Navonil. (2012). A Survey of Serious Games on Sustainable Development, Proceedings of the 2012 Winter Simulation Conference. https://doi.org/10.1109/WSC.2012.6465182

Koumje, G. F. (2018). The didactics of bilingual education: Disciplinary teaching and language. International Journal of Educational Technology and Learning, 4(1), 8-12. https://doi.org/10.20448/2003.41.8.12

McClarty, K., Orr, A., Frey, P.M., Dolan, R.P., Vassivela, V., McVay, Aaron. (2012). Literature Review of Gaming in Education, Research Report, Pearson.

Moustafa, H., Tourkia, F. B., \& Ramadan, R. M. (2017). Application of Artificial Neural Networks Modeling for Evaluation of ELearning/Training Convergence Time. American Journal of Education and Learning, 2(2), 159-179. https://doi.org/10.20448/804.2.2.159.179

Muruganantham, D. (2015). Developing of E-content package by Using ADDIE model. International Journal of Applied Research, 1(3), 52-54. 
Okpiliya, F. I., Osah, C., Okwakpam, I., \& Ekong, A. (2016). Spatial variability in the distribution of migrants and indigenous labour force among oil companies in Ogba/Ndoni/Egbema local government area of rivers state. Humanities and Social Sciences Letters, 4(4), 84-95. https://doi.org/10.18488/journal.73/2016.4.4/73.4.82.93

Tabar, C. (2018). The Rwandan Secondary School Competence-Based Curriculum: Knowledge, Skills and Attitudes to Incorporate in the University of Rwanda-College of Education Programs to Align them with the Current Curriculum. International Journal of Education and Practice, 6(2), 64-75. https://doi.org/10.18488/journal.61.2018.62.64.75

Wang, Z., Cheng, L., \& Wang, H. (2017). A Study on the Training Mode of Electronic Application-Oriented Undergraduate with Industry Needs. Journal of Education and e-Learning Research, 4(2), 37-40. https://doi.org/10.20448/journal.509.2017.42.37.40

Waranurastuti, V. (2013). Rangkuman Ilmu Pengetahuan Umum Terlengkap, Dunia Cerdas, Jakarta Timur. 